a slow release of desferrioxamine into the body. There would be a potentially large world market.

${ }^{1}$ Heinrich, H C, et al, Zeitschrift für Kinderheilkunde, 1973, 115, 1.

${ }^{2}$ Engle, M A, Annals of the New York Academy of Sciences, 1964, 119, 694.

${ }^{3}$ Barry, M, et al, British Medical fournal, 1974, 2, 16.

4 Modell, C B, and Beck, J, Annals of the New York Academy of Sciences, 1974, 232, 201

5 Iancu, T C, Neustein, H B, and Landing, B H, in Iron Metabolism. Ciba Foundation Symposium 51 (New Series), p 293. Amsterdam, Elsevier/ North Holland, 1977.

6 Thompson, R B, Owen, D M, and Bell, W N, American fournal of the Medical Sciences, 1967, 253, 453.

${ }^{7}$ Propper, R D, Shurin, S B, and Nathan, D G, New England Fournal of Medicine, 1976, 294, 1421.

${ }^{8}$ Hussain, M A M, et al, Lancet, 1976, 2, 1278.

${ }^{9}$ Propper, R D, et al, New England Fournal of Medicine, 1977, 297, 418.

10 Pippard, M J, Callender, S T, and Weatherall, D J, Clinical Science and Molecular Medicine, 1978, 54, 99.

${ }^{11}$ Hussain, M A M, et al, Lancet, 1977, 1, 977.

12 Cohen, A, and Schwartz, E, Fournal of Pediatrics, 1978, 92, 643.

13 Cumming, R L C, et al, British fournal of Haematology, 1969, 17, 257.

14 Pippard, M J, and Callender, S T, Paper presented at the meeting of the European Iron Club, Noordwijkerhout, Netherlands, May 1978.

15 Pippard, M J, et al, Lancet, 1978, 1, 1178.

16 Ciba Pharmaceutical Company, Clinical Pharmacology and Therapeutics, 1969, 10, 595.

17 Modell, B, Archives of Disease in Childhood, 1977, 52, 489.

\section{Tricyclic antidepressant concentrations and clinical response}

At least one in every four depressed patients responds inadequately to tricyclic antidepressants. One explanation is the wide variation in the individual plasma concentrations of these drugs. The unanswered question is whether the failure rate could be reduced by monitoring pharmacokinetic factors such as "steady-state" plasma concentrations.

Most studies have concerned nortriptyline, simply because techniques for measuring it were developed early and because interpreting the results is not complicated by the presence of active metabolites. In the initial limited Scandinavian study ${ }^{1}$ both low concentrations $(<50 \mu \mathrm{g} / \mathrm{l})$ and high concentrations $(>150 \mu \mathrm{g}$ 1) of nortriptyline after two weeks' treatment seemed to be associated with a poor clinical response. This was confirmed in a trial of 30 patients, in whom seven of 11 non-responders had concentrations over $170 \mu \mathrm{g} / \mathrm{l}$; within a week of reducing dosage five of the seven were well, ${ }^{2}$ a finding later repeated. ${ }^{3}$ Similarly, in an American study ${ }^{4}$ with 18 outpatients the nine with plasma nortriptyline concentrations between 50 and $139 \mu \mathrm{g} / 1$ showed more improvement after six weeks than those with concentrations above this range; and an English study 5 of 36 depressed inpatients again supported this. By contrast, two Australian studies ${ }^{6}$ and an earlier English one ${ }^{8}$ found no relation between nortriptyline concentrations and clinical response, and the results in yet another Scandinavian evaluation ${ }^{9}$ were unconvincing.

None of these clinical studies included comprehensive pharmacokinetic estimations. The recently published data of Montgomery and his associates, however, provide strong evidence that high plasma nortriptyline concentrations-in this instance over $200 \mu \mathrm{g} / \mathrm{l}$-are significantly less effective than intermediate ones. After receiving only a placebo for several days 18 depressed inpatients were given nortriptyline, $100 \mathrm{mg}$ at night for four weeks. Plasma concentrations at the end ranged from 120 to $681 \mu \mathrm{g} /$. For the first two weeks the clinical response was unrelated to concentration, but those with concentrations below $200 \mu \mathrm{g} / 1$ continued to respond over the third and fourth weeks, whereas those with high concentrations improved no further. One patient with high concentrations became confused, but otherwise side effects were not related to drug concentrations. High plasma concentrations cannot, apparently, be guessed at on clinical grounds alone.

In the pharmacokinetic study ${ }^{11}$ nortriptyline concentrations were measured for 48 hours after a single 100-mg dosebefore the course' of treatment. The mean plasma clearance of the drug in the patients was unexpectedly only about half that of normal people $(26.1 v 52.61 / \mathrm{h})$, which accounted for the high plasma concentrations found later with continuous treatment. Montgomery et al suggest that this finding may reflect preselection of patients: those who respond are treated successfully by general practitioners, while those who do not, who have a slow clearance and high antidepressant concentrations, are referred to hospital. The results of the pharmacokinetic study imply that a single estimation of plasma nortriptyline 48 hours after a test dose will accurately predict eventual steady-state concentrations, and hence could be used to adjust clinical dosage.

What about amitriptyline, which in Britain we use much more than nortriptyline? Amitriptyline is extensively metabolised to nortriptyline by $N$-desmethylation, so that after taking amitriptyline for a few weeks the concentration of nortriptyline is similar to that of amitriptyline. The earliest report ${ }^{12}$ claimed a strong correlation between plasma tricyclic concentrations and clinical response, and similar results were reported by workers in St Louis ${ }^{13}{ }^{14}$ and Pittsburg: ${ }^{15}$ the higher the concentration of tricyclics, the better the response. There was no apparent curvilinear relation to concentration, as with nortriptyline. An attempt to replicate the earlier results in a multicentre WHO collaborative study on 54 patients was unsuccessful $^{16}$; this study has been criticised $^{17}$ as untypical, however, because the clinical response of the patients was so dismal. Studies with other antidepressants have been too few to permit conclusions.

The lack of consistency in these studies may be due to technical problems with estimating drug concentrations; different ways of evaluating clinical response and types of patient; and further pharmacokinetic factors, such as differences in plasma binding. Other pharmacological problems include extrapolation from plasma concentrations to those at the presumed site of action and differences in the sensitivity of effector systems; attempts have been made to correlate clinical response with pharmacodynamic responses such as inhibition of the tyramine pressor response.

Nevertheless, we now have good evidence that the clinical response to nortriptyline is related to concentrations below about $200 \mu \mathrm{g} / 1$ and above $50 \mu \mathrm{g} / \mathrm{l}$. Why the higher concentrations should be ineffective is unknown. The new rapid and cheap immunoassay techniques for estimating tricyclic antidepressives should hasten the translation of these research findings into routine clinical practice. We could increase the efficacy of nortriptyline at least by monitoring plasma concentrations to predict the correct dosage.

${ }^{1}$ Asberg, M, et al, British Medical fournal, 1971, 3, 331.

2 Kragh-Sørensen, P, Asberg, M, and Eggert-Hansen, C, Lancet, 1973, 1, 113.

${ }^{3}$ Kragh-Sørensen, P, et al, Psychopharmacologia, 1976, 45, 305.

4 Ziegler, V E, et al, Clinical Pharmacology and Therapeutics, 1976, 20, 458.

${ }^{5}$ Montgomery, S, Braithwaite, R A, and Crammer, J L, British Medical Fournal, 1977, 2, 166.

${ }^{6}$ Burrows, G D, Davies, B, and Scoggins, B A, Lancet, 1972, 2, 619.

${ }^{7}$ Burrows, G D, et al, Clinical Pharmacology and Therapeutics, 1974, 16, 639.

${ }^{8}$ Lyle, W H, et al, Postgraduate Medical fournal, 1974, 50, 282. 
9 Asberg, M, Clinical Pharmacology and Therapeutics, 1974, 16, 215.

10 Montgomery, S, et al, Clinical Pharmacology and Therapeutics, 1978, 23, 309.

11 Braithwaite, R, Montgomery, S, and Dawling, S, Clinical Pharmacology and Therapeutics, 1978, 23, 303.

12 Braithwaite, R A, et al, Lancet, 1972, 1, 1297.

13 Ziegler, V E, et al, Clinical Pharmacology and Therapeutics, 1976, 19, 795.

14 Ziegler, V E, Clayton, P J, and Biggs, J T, Archives of General Psychiatry, $1977,34,607$.

15 Kupfer, D J, et al, Clinical Pharmacology and Therapeutics, 1977, 22, 904.

16 Coppen, A, et al, Lancet, 1978, 1, 63.

17 Potter, W Z, and Goodwin, F K, Lancet, 1978, 1, 1049.

\section{Controlled intravascular sodium nitroprusside treatment}

Controlled intravascular infusion of sodium nitroprusside is being used in a growing list of clinical conditions. These include the treatment of refractory hypertensive crises, reduction in cardiac afterload in left ventricular dysfunction, controlled hypotension during surgery, the postoperative control of haemorrhage, control of dissecting aortic aneurysms, and the treatment of peripheral ischaemia induced by ergotamine. ${ }^{1-3}$ The drug acts locally on vascular smooth muscle, causing vasodilatation and so reducing both systemic and pulmonary arterial and venous pressures. Its effect has a rapid onset, and its pharmacological effects are reversed within a few minutes of stopping the infusion. Though the treatment is usually straightforward, complications have been reported, with at least three deaths. ${ }^{4}$ The safe use of sodium nitroprusside depends on knowledge of its potential toxicity and an appreciation of the variability of pharmacological responses. Treatment should be carried out only in units with staff who are aware of the possible hazards and in which continuous cardiovascular monitoring and a rapid clinical chemistry service are available.

That sodium nitroprusside can give rise to cyanide has been recognised from animal and clinical studies. ${ }^{56}$ It penetrates erythrocytes, where electron transfer from haemoglobin iron to nitroprusside yields methaemoglobin and an unstable nitroprusside radical. This breaks down, liberating all five cyanide radicals, one of which is trapped by the methaemoglobin. ${ }^{7}$ Though some breakdown of nitroprusside may also occur in plasma some of the liberated cyanide diffuses into erythrocytes, adding to that produced through the reaction with haemoglobin. ${ }^{8}$ Indeed, only a small proportion of the cyanide produced from an infusion is found in plasma, and the remainder (over $90 \%$ ) is within erythrocytes. Vesey $e t a l^{8}$ have shown that immediately after an infusion of sodium nitroprusside $98 \%$ of the total blood cyanide is in erythrocytes; part is bound as cyanmethaemoglobulin but the major fraction is fixed in an undefined way. Since erythrocyte cyanide is firmly bound the freely diffusible plasma cyanide is probably the main determinant of toxicity. ${ }^{9}$ The plasma fraction readily diffuses into tissue fluids, including cerebrospinal fluid, ${ }^{10}$ and produces a cytotoxic hypoxia by inhibiting tissue cytochrome oxidase activity. In one death associated with the use of sodium nitroprusside ${ }^{11}$ the blood cyanide concentration was compatible with lethal acute cyanide poisoning. ${ }^{12}$ Nevertheless, serial measurements of whole blood cyanide or plasma thiocyanate concentrations may not be a reliable guide to the toxicity of exposure to cyanide derived from nitroprusside, since the erythrocytebound cyanide has no toxicological importance.

When sodium nitroprusside is given by infusion the rate of detoxification of cyanide to thiocyanate is such that the rise in plasma thiocyanate concentration is slow. ${ }^{13}$ Furthermore, since plasma thiocyanate concentrations are normally high and show a wide scatter, ${ }^{14}$ the rise expected from short-term infusions may not be detected easily. Measuring plasma thiocyanate concentrations may be of more value with prolonged infusions..$^{13}$ Plasma cyanide is probably the major determinant of toxicity and its concentration provides a more reliable guide: the concentration should not be allowed to rise above $3 \mu \mathrm{mol} / 1 .^{15}$

The toxicity of sodium nitroprusside appears to be related to the rate of infusion rather than to the total amount infused. This difference requires to be clearly appreciated: recommendations quoted specifically as maximum doses without reference to infusion times are toxicologically meaningless. The rate of infusion will normally be determined by the pharmacological response. Usually the hypotensive response to low dosages $(<10 \mu \mathrm{g} / \mathrm{kg} / \mathrm{min}$ ) is constant, but any of three abnormal therapeutic responses may occur. Firstly, the response may be constant but require continual high dosage $(>10 \mu \mathrm{g} / \mathrm{kg} / \mathrm{min})$; secondly, there may be tachyphylaxis (a decreasing response to constant dosage); and, thirdly, there may be resistance to the drug's action. ${ }^{4}$ Patients who show any of these abnormal responses are at risk of toxic complications.

Another complication of treatment, confirmed biochemically in several centres, is metabolic acidosis. Again, it is most likely to occur in patients treated at high rates of infusion. Inhibition of tissue cytochrome oxidase activity by cyanide causes a shift from aerobic to anaerobic metabolism with accumulation of lactate, increased tissue ADP, decreased tissue ATP and phosphocreatine, and decreased production of carbon dioxide. Arterial blood analysis shows a pattern of metabolic acidosis with respiratory compensation with increased lactate, decreased bicarbonate, $\mathrm{pH}$ and $\mathrm{PaCO}_{2}$, and negative base excess. With cytotoxic hypoxia the arterial $\mathrm{Po}_{2}$ is usually high, but in congestive cardiac failure a decrease in $\mathrm{PO}_{2}$ may result from increased perfusion of underventilated pulmonary units. ${ }^{16}$ Metabolic acidosis may occur when erythrocyte cyanide concentrations exceed $75 \mu \mathrm{g} / 100 \mathrm{ml}$ in the absence of concomitant cyanide antidotes.

In view of the potential complications of intravascular sodium nitroprusside treatment, care is needed in choosing and monitoring patients. Patients should not be considered for prolonged intravascular treatment if they have advanced liver or kidney disease, malnutrition, vitamin $\mathrm{B}_{12}$ deficiency, Leber's hereditary optic atrophy, or tobacco amblyopia. The dose rate should be kept down to the minimum by using a constant-rate infusion pump and continuously monitoring arterial pressure. Rates over $10 \mu \mathrm{g} / \mathrm{kg} / \mathrm{min}$ cause a lactic acidosis. ${ }^{418}$ A rate of $10 \mu \mathrm{g} / \mathrm{kg} / \mathrm{min}$ has been found to be suitable for children, ${ }^{19}$ but this should be regarded as the upper safe limit and lower infusion rates should be used if possible. At higher rates careful continuous monitoring is essential; at lower rates the bicarbonate, lactate, $\mathrm{pH}$, and arterial $\mathrm{PO}_{2}$ and $\mathrm{PCO}_{2}$ should be measured at frequent intervals.

Materials for the supportive and antidotal treatment of cyanide poisoning should be available. Intravenous administration of cobalt salts or sodium nitrite may have several toxicological and pharmacological disadvantages; the use of hydroxocobalamin and sodium thiosulphate is preferable. Hydroxocobalamin combines with cyanide to form cyanoco- 